\title{
Erratum to: Study on Isothermal Formation Dynamics of Calcium Barium Sulphoaluminate Mineral
}

\author{
Yongbo Huang $\cdot$ Shoude Wang $\cdot$ Chenchen Gong • \\ Yanting Zhao $\cdot$ Lingchao Lu
}

Published online: 3 July 2013

(C) Springer Science+Business Media New York 2013

Erratum to: J Inorg Organomet Polym

DOI 10.1007/s10904-013-9883-0

The authors missed the inclusion of an "Acknowledgement" section in the original publication. This section is given below.

Acknowledgments This work was supported by Natural Science Foundation of China (No. 51272091 and No. 51102113) and School Key Foundation of University of Jinan (No. XKY1002). The work was also supported by Program for Scientific Research Innovation Team in Colleges and Universities of Shandong Province.

The online version of the original article can be found under doi:10.1007/s10904-013-9883-0.

Y. Huang · S. Wang $(\bowtie) \cdot$ C. Gong · Y. Zhao · L. Lu Shandong Provincial Key Laboratory of Preparation and Measurement of Building Materials, University of Jinan, Jinan 250022, China

e-mail: personand98@163.com 